\title{
Assessing Urban Forest Canopy Cover Using Airborne or Satellite Imagery
}

\author{
Jeffrey T. Walton, David J. Nowak, and Eric J. Greenfield
}

\begin{abstract}
With the availability of many sources of imagery and various digital classification techniques, assessing urban forest canopy cover is readily accessible to most urban forest managers. Understanding the capability and limitations of various types of imagery and classification methods is essential to interpreting canopy cover values. An overview of several remote sensing techniques used to assess urban forest canopy cover is presented. A case study comparing canopy cover percentages for Syracuse, New York, U.S. interprets the multiple values developed using different methods. Most methods produce relatively similar results, but the estimate based on the National Land Cover Database is much lower.
\end{abstract}

Key Words. Remote sensing; urban tree canopy.

\section{Urban Forest Canopy Cover}

Urban forest canopy cover, the area covered by tree and shrub canopies in an urbanized or developed region, is a fundamental measure of urban forest structure (Nowak 1994). The structure of the urban forest determines its ecologic functioning (Zipperer et al. 1997), including the many benefits the urban forest provides (Dwyer et al. 1992; Nowak and Dwyer 2007) as well as influencing actions needed to manage the forest. Benefits directly related to the amount of urban forest canopy cover include air pollutant removal, stormwater runoff reduction, and building energy conservation. Urban tree management actions are also related to the quantity of biomass, and therefore canopy cover, in a particular area.

Specifically, urban forest canopy cover is the two-dimensional, orthogonal projection of tree and shrub canopies onto the plane of the ground surface. For a given area, urban forest canopy cover has two important properties: quantity and spatial distribution. The quantity is represented as a proportion or percentage of the area covered by tree and shrub canopies when viewed from directly above. It can be used to compare regions in terms of their forest cover and track an area's urban forest change over time. As Poracsky and Lackner (2004) note, canopy cover is also easily understood by the general public and is therefore a useful tool for communicating urban forestry issues. Spatial distribution is best displayed as a map and shows the location of tree cover in the area of interest. While the spatial distribution of urban forest canopy cover is exclusively determined by aerial or satellite-based remote-sensing techniques, the quantity can also be estimated through the use of field plots or dot grid photograph interpretation. Urban forest canopy cover does not directly provide information about the species composition, number of trees, or health of the urban forest, but these quantities can be inferred through the combined use of groundbased sampling.

\section{Measuring Urban Forest Canopy Cover Via Remote Sensing}

Urban forest canopy has been quantified using aerial photograph interpretation techniques (Rowntree 1984; Nowak et al. 1996) and classification of high-resolution digital imagery (Myeong et al. 2001; Zhang 2001; Irani and Galvin 2002), mediumresolution satellite imagery (Wang 1988; Iverson and Cook 2000; Huang et al. 2001), and low-resolution satellite imagery (Zhu 1994; Dwyer et al. 2000). Each technique and imagery format provides certain advantages and possibly disadvantages for the assessment of urban forest canopy cover.

\section{Aerial Photograph Interpretation}

Interpretation of aerial photographs at randomly placed locations in a study area has been used to determine the quantity of urban forest cover (Rowntree 1984; Nowak et al. 1996). The presence or absence of tree canopy cover at the specific point position is tallied for each of the sample points, and the proportion of sample points that fell on the tree canopy statistically represents the amount of urban forest canopy cover in the study area. A standard error of the sampling can also be computed to yield a bound on the canopy percent estimate. With the wide availability of digital orthophotographs and geographic information systems in many municipalities, aerial photograph interpretation is very simple to implement. It yields very good results for quantity, but provides limited information on the spatial distribution of the forest cover. Aerial photograph interpretation requires little technical remote-sensing knowledge beyond the ability to interpret tree canopies. Tools to aid in digital aerial photograph interpretation are available at www.fs.fed.us/ne/syracuse/Tools/ tools.htm.

Several properties of the aerial imagery itself can influence the ease of interpretation and quality of results. Imagery acquired during the leaf-on season for trees will be more straightforward to interpret than leaf-off imagery. Leaf-off imagery may still be used for photograph interpretation, but more interpretation skill and time is required to infer canopy from the visible branch structure and/or shadows of the stem and branches on the ground surface. Resolution for digital images, or scale for traditional print photographs, should be such that individual trees can clearly be discerned. For digital imagery, this resolution would generally be approximately $1 \mathrm{~m}(3.3 \mathrm{ft})$ or smaller. The drawback of very high-resolution imagery is that the digital files will 
be quite large and it may be time-consuming to change views from one point to another. Color infrared (CIR) imagery is useful in differentiating various types of vegetation because CIR can accentuate the subtle differences between types of trees, between grass and trees, and between vegetation and nonvegetative surfaces. On all types of aerial and satellite images, trees overlap other ground surfaces such as buildings, roads, or parking lots (impervious surfaces) and bare soil, grass, or shrubs (permeable surfaces). Because the understory or ground cover cannot usually be seen, assessments of the full extent of surface features and canopy depth, useful for watershed analyses, for example, cannot be exactly determined from leaf-on aerial photographs or optical remotely sensed imagery.

\section{Types of Digital Imagery}

Several different types of digital aerial or satellite imagery have been used to assess urban forest canopy cover, including highresolution digital aerial photographs, high-resolution satellite imagery, medium-resolution satellite imagery, and low-resolution satellite imagery.

High-resolution digital frame cameras have recently been used in place of traditional film aerial cameras (Myeong et al. 2001; Zhang 2001). The resulting imagery has the three portions of the spectrum (either red, green, and blue or near infrared [NIR], red, and green) separated into individual bands that can be used in further automated processing. These cameras generally produce images with submeter to meter spatial resolution, i.e., each image pixel represents an area on the ground $1 \mathrm{~m} \times 1 \mathrm{~m}$ square or smaller. Emerge DSS (Applanix Corp., Richmond Hill, Ontario, Canada) and Leica ADS40 (Leica Geosystems AG, Heerbrugg, Switzerland) are examples of airborne sensor systems that produce this type of imagery.

High-resolution aerial and satellite imagery has been used to map urban forest cover in many cities, including Baltimore and Annapolis, Maryland, U.S. (Irani and Galvin 2002; Galvin et al. 2007); Syracuse, New York (Myeong et al. 2001); and New York City (www.oasisnyc.net/oasismap.htm). The most common high-resolution satellite imagery, from the Quickbird and IKONOS satellites, consists of four multispectral bands (NIR, red, green, and blue) with spatial resolution of $2.4 \mathrm{~m}(7.9 \mathrm{ft})$ (Quickbird) or $4 \mathrm{~m}$ (13.2 ft) (IKONOS) coupled with a $1 \mathrm{~m} \mathrm{(3.3}$

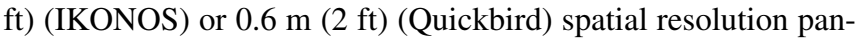
chromatic band. The multispectral bands can be combined with the higher resolution grayscale panchromatic band to produce "pansharpened" multispectral imagery at the higher resolution. These sensors have enough spectral coverage to allow the imagery to be used successfully in automated classification algorithms. The spatial resolution is adequate to identify canopies of individual, open-grown trees.

Medium-resolution satellite imagery, with spatial resolution of tens to a few hundred meters, lends itself to analysis of forest cover of entire cities or regional urbanized areas. This spatial resolution depicts areas that can have several land cover types in an individual pixel. For example, in a residential area, tree canopies, building roofs, lawns, and paved streets could be represented within a single pixel. These "mixed pixels" are suited for specialized subpixel processing methods that are discussed subsequently. Enhanced Thematic Mapper (ETM) on the Landsat series of Earth imaging satellites is one of the most common examples of medium-resolution satellite imagery. Landsat's
ETM captures six multispectral bands, three in the visible part of the spectrum and the remainder in the NIR and midinfrared portion of the spectrum. Because living vegetation is highly reflective in the NIR, these bands facilitate the differentiation of vegetated surfaces from other land cover. Landsat imagery has been used to map urban tree cover (e.g., Wang 1988; Iverson and Cook 2000). In recent classifications from the National Land Cover Database (NLCD) 2001 (Homer et al. 2007), a tree canopy layer is derived from Landsat ETM imagery and is being used to assess urban forest cover across the United States as part of the USDA Forest Service's Resources Planning Act (RPA) program.

Satellite imagery with a spatial resolution of several hundred meters and larger can be considered low resolution. Because of the complex mixing of land cover in developed areas and the large ground size of the pixels, low-resolution imagery is of limited usefulness for most urban forest cover mapping unless specialized subpixel analysis techniques are used. These techniques provide percent forest cover in each pixel and are described in the next section. Advanced Very-High Resolution Radiometer (AVHRR) imagery with $1.1 \mathrm{~km}(0.66 \mathrm{mi})$ spatial resolution has been used to assess urban forest cover in all the cities of the coterminous United States but had various limitations (Zhu 1994; Dwyer et al. 2000). The AVHRR sensor, primarily used for weather observations, collects data in one band in the green, one band in the reflected NIR, and three bands of the thermal parts of the spectrum so it is of marginal usefulness for general land cover mapping. The combination of low spatial and spectral resolutions of AVHRR produces highly variable results for urban forest cover mapping (Walton 2008).

\section{Classification of Digital Imagery}

Urban forest canopy cover can be mapped using the imagery described previously and one of many image classification techniques, including normalized difference vegetation index (NDVI), pixel-based, and object-oriented classification of highresolution images and subpixel estimation of medium-resolution imagery.

Normalized Difference Vegetation Index. The NDVI is a very simple method used to accentuate vegetation from imagery containing reflectance in the red and the NIR portions of the spectrum. It is computed using the NIR and red (R) reflectance bands in the ratio as shown in Equation (1). The index produces high (brighter) values for pixels that contain more vegetation, but because it is a simple ratio, there can be other areas in an image such as sun glint from water surfaces that also produce high NDVI values. In addition, NDVI can be influenced by external factors (e.g., view angle, leaf orientation, and soil background; Campbell 2007) so that it does not produce a linear scale that is in direct proportion to the percentage of vegetation in the pixel.

$$
\mathrm{NDVI}=\frac{(\mathrm{NIR}-\mathrm{R})}{(\mathrm{NIR}+\mathrm{R})}
$$

Early remote-sensing analysis of urban forests using multispectral imagery such as that by the nonprofit group American Forests in the mid-1990s used the NDVI band ratio directly as a simple classification of urban forest cover. This approach is very limited because NDVI includes all vegetation and does not produce values that are linearly proportional to the amount of 
forest cover. Currently, NDVI is often used as an auxiliary input layer for other automated classification algorithms (e.g., Myeong et al. 2001).

High-Resolution Image Classification. Classification of highresolution images poses difficulties for algorithms because the size of an individual pixel is much smaller than the size of the object to be classified resulting in pixels of different spectral characteristics making up the same object. Tree canopies, for example, when viewed on submeter high-resolution imagery, are made up of pixels representing various levels of reflectance from the vegetated surfaces as well as pixels of shaded areas. This disparity of the constituents of urban forest cover makes it difficult to classify tree canopies from their spectral signature alone. Several studies (Myeong et al. 2001; Zhang 2001; Irani and Galvin 2002) have used texture measures and, more recently, object-based methods (Walker and Briggs 2007; Zhou and Troy 2008) have been applied to high-resolution image classification of urban forest cover to overcome the difficulties presented by varying reflective properties among pixels representing one category.

One of the primary difficulties in classifying urban forest cover is the differentiation between tree canopies and grass surfaces. At an individual pixel level, tree canopies and grass surfaces generally have a very similar spectral response. However, tree canopies generally contain areas of bright, higher reflectance values from vegetation surfaces and areas of darker, low reflectance values from the shadowy regions of the tree canopy. This effect creates a more coarse texture on the image of a tree canopy when compared with other vegetated surfaces such as grassy lawns or athletic fields, which generally have a smoother, finer texture. Algorithms designed to identify regions of coarse texture have been shown to be very useful in differentiating tree and shrub canopies from other vegetation surfaces (Myeong et al. 2001; Zhang 2001).

Another method to handle highly variable pixel characteristics of urban forest canopy is through the use of object-based classification. Images are segmented into clusters of similar pixels by considering any number of pixel-based metrics such as spectral or textural values. These segments, or objects, are then combined to form the final classification categories. Considering objects rather than individual pixels yield results that mimic human classification. Object-based image analysis has been used by Walker and Briggs (2007), O'Neil-Dunne (2007), and Galvin et al. (2007). Zhou and Troy (2008) classified urban land cover at the parcel level using object-oriented techniques. Object-based analyses can integrate many different types of input data. Airborne LIDAR (laser ranging) data have been used to incorporate vegetation height information into the classification process (O’Neil-Dunne 2007).

Subpixel Estimation. Traditionally, techniques using mediumresolution imagery have used "whole-pixel" classifications in which each pixel is designated as either "forested" or "not forested" with some threshold being used to determine the cutoff between the two classes. Because of the heterogeneous nature and number of mixed pixels in urban areas, whole-pixel classifications tend to misrepresent the amount and spatial distribution of urban forest cover. For subpixel urban forest cover, the goal is to estimate the percent tree canopy cover for each pixel as a real number between zero and 100. Zhu (1994) developed a subpixel forest density map using a regression procedure from $1.1 \mathrm{~km}(0.66 \mathrm{mi})$ AVHRR multispectral imagery, which was later used to assess urban forest cover by Dwyer et al. (2000). The nonprofit group American Forests (2007) has used the ERDAS Imagine Subpixel Classifier (Applied Analysis, Inc., www.discover-aai.com/software/products/IMAGINE_Subpixel_ Classifier.htm) to map and assess change of urban forest canopy. Small (2001) and Small and Lu (2006) have used spectral mixture modeling to estimate subpixel vegetation abundance in the New York City region. Recently, with the subpixel tree canopy layer from the NLCD 2001 (Homer et al. 2007), urban forest cover and accuracy assessments are being conducted using this $30 \mathrm{~m}$, nationwide resource by the USDA Forest Service, Syracuse, New York. The NLCD 2001 tree canopy estimate was generated using the Cubist (RuleQuest Research, www.rulequest. com) rule-based regression software (Huang et al. 2001).

Subpixel urban forest cover maps generally represent the amount and spatial distribution of urban forest canopy cover better than whole-pixel classification techniques for mediumresolution imagery.

Classification Accuracy Assessment. For all methods of digital image classification, an accuracy assessment of the map should be conducted to determine how accurately the map categories (e.g., tree cover) were classified. One relatively simple way to determine map classification accuracy is to randomly sample points throughout the classified area and ground-truth the classification at those points either through site visits or aerial photograph interpretation. The map classification at each point is then compared with the ground-truth estimate to determine map classification accuracy (Table 1). Typically, overall map accuracies within the $80 \%$ to $90 \%$ accuracy range can be obtained, but accuracy varies among individual classification categories. As a result of the varying classification techniques and imagery products, understanding map classification accuracy is essential to understanding how useful the map will be for planning, management, and analysis purposes.

\section{Assessing Urban Forest Canopy Change}

Many of these map products discussed here can be used as the basis of urban forest canopy change studies. These assessments can vividly demonstrate the effects of urbanization on the forest canopy resource and bolster public opinion with regard to local land development policies. Understanding how urban forest canopy cover is changing can be valuable information for the forest managers. Several groups have used imagery as the means to assess canopy cover change, including the nonprofit group American Forests (2007) in several U.S. cities and Poracsky and Lackner (2004) in Portland, Oregon. Two important factors in determining canopy cover change are 1) assessing change over a long enough time period for change to be evident; and 2) having a consistent methodology when developing each individual canopy map that is compared (Walton 2008). A consistent methodology will include using similar imagery and analysis methods when developing both products used in the comparison.

\section{Comparison Case Study}

To illustrate how different methods and imagery can lead to differing canopy cover estimates and accuracy, the results of several urban forest canopy cover assessments of Syracuse, New 
Table 1. Accuracy assessment of cover classification for Syracuse, New York, using high-resolution digital color infrared imagery.*

\begin{tabular}{|c|c|c|c|c|c|c|c|c|}
\hline \multirow[b]{2}{*}{ Class name } & \multicolumn{5}{|c|}{ Reference } & \multirow[b]{2}{*}{ Row total } & \multirow[b]{2}{*}{$\begin{array}{l}\text { User's } \\
\text { accuracy }(\%)\end{array}$} & \multirow[b]{2}{*}{$\begin{array}{l}\text { Standard } \\
\text { error }(\%)\end{array}$} \\
\hline & Tree/shrub & Grass/herbaceous & Bare soil & Water & $\begin{array}{l}\text { Impervious } \\
\text { surface }\end{array}$ & & & \\
\hline Tree/shrub & 25.0 & 3.75 & 0.0 & 0.0 & 0.25 & 29 & 86.2 & 3.2 \\
\hline Grass/herb & 3.5 & 13.0 & 0.75 & 0.0 & 1.5 & 18.75 & 69.3 & 5.4 \\
\hline Bare soil & 0.0 & 0.0 & 0.5 & 0.0 & 0.75 & 1.25 & 40.0 & 24.5 \\
\hline Column total & 30.75 & 21.25 & 2.25 & 6.5 & 39.25 & 100 & & \\
\hline Producer's accuracy (\%) & 81.3 & 61.2 & 22.2 & 100.0 & 93.6 & & Overall 81.75 & \\
\hline Standard error $(\%)$ & 3.5 & 5.3 & 14.7 & 0.0 & 2.0 & & & Overall 1.9 \\
\hline
\end{tabular}

*Myeong et al. (2001). Error matrix entries are based on percent of 400 ground-truth points.

York, are compared. The intent of this comparison is to show variation in results, validity of results within the limitations of the method, and to indicate if the result represents a bona fide change in canopy cover.

\section{METHODS}

The location of this study is the city of Syracuse, New York. All estimates of urban forest canopy cover have been generated using the political boundaries of Syracuse. Each estimate was compiled using different imagery sources and methods.

Three photograph interpretation results were compared. The first estimate was taken directly from Rowntree (1984) and used photographic prints. Additionally, digital images from 1999

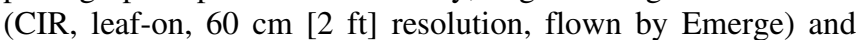
from 2003 (New York State Orthoimages, natural color, leaf-off, $30 \mathrm{~cm}$ [1 ft] resolution) were photographically interpreted at 300 random point locations as either "tree canopy" or "nontree canopy". The proportion of the area covered by the tree canopy was recorded and standard sampling error was calculated.

A $60 \mathrm{~cm}(2 \mathrm{ft})$ resolution forest canopy map was created using digital classification methods from the 1999 Emerge digital imagery (Myeong et al. 2001) and then summarized inside the city boundary. The accuracy of the forest canopy map as calculated by Myeong et al. (2001) is $82 \%$ (Table 1).

Medium-resolution (30 m [99 ft]) Landsat imagery was used to calculate subpixel urban forest canopy cover maps of Syracuse. Two methods were followed. The first method was an analysis specific to Syracuse, which used local training data and imagery clipped to the immediate region containing the city boundary. This method resulted in a pixel mean absolute error (MAE) of $11.7 \%$. The second Landsat-based subpixel estimation was from the NLCD 2001 (Homer et al. 2007). This is a nationwide forest cover product produced by the U.S. Geological Survey and its cooperators. Training data for this estimation are collected throughout a regional mapping zone and may be entirely from rural forests. The NLCD has a quality standard of a MAE less than $15 \%$ for the mapping zone, which was followed for the creation of this data set.

Low-resolution (1.1 km [0.66 mi]) AVHRR imagery was used to calculate a subpixel forest density map of the entire United States (Zhu 1994) and summarized within the Syracuse boundary. This same forest cover map was summarized for the 2000 RPA assessment by Dwyer et al. (2000) after removing the water-covered regions.
Imagery-based estimates of urban forest canopy cover are also compared with ground estimates. Ground estimates followed the standard Urban Forest Effects model canopy cover estimation protocol (Nowak et al. 2005) and involve an ocular estimate to the nearest $5 \%$ from under the tree canopy on approximately 200 one-tenth acre $(0.04$ ha $[0.1 \mathrm{ac}])$ plots. At the individual plot level, consensus estimates are recorded from a two-person crew using a cover template, but estimates are difficult to replicate precisely as a result of the subjectivity from one interpreter to another. Once many sample plots are accumulated, relatively consistent results are obtainable. Three estimates from field sampling conducted in 1999, 2001, and 2004 are included in this comparison.

\section{RESULTS}

The urban forest canopy cover percentage values were generally in the low to mid-20s with one notable outlier of $12.7 \%$ calculated from the NLCD 2001 tree canopy layer (Table 2).

\section{DISCUSSION}

All but one of the eleven percent canopy cover values are within a range of $5.2 \%$. When the sampling errors or accuracy estimates are taken into consideration, differences between the values are indistinguishable and are within the limitations of each method. Thus, all three general types of cover classification methods (photograph interpretation, digital image classification, and ground estimates) can produce reasonable estimates of overall canopy cover that are likely within a few percent of the actual tree cover value. However, the NLCD cover estimates using Landsat $30 \mathrm{~m}$ data and regional training data tend to produce an underestimate of canopy cover (12.7\% estimate). The underestimate is consistent with a 36-city comparison of NLCD-derived values to photograph-interpreted reference data (Walton 2008). The underestimate is most likely as a result of NLCD being created using rural forest training data sets in the development of the estimation algorithms. Future research needs to investigate whether the NLCD tree canopy cover estimates are consistently low among other U.S. urban areas. Using local training data, 30 $\mathrm{m}$ Landsat imagery produced a more reasonable result for Syracuse, New York.

The small differences between the AVHRR-based values and the other values show good agreement among the methods for Syracuse. However, an assessment of the AVHRR-based data in other cities reveals that it is highly variable and should not be 
Table 2. Urban forest canopy cover comparison for Syracuse, New York. ${ }^{z}$

\begin{tabular}{|c|c|c|c|c|c|}
\hline Method & Imagery & Year & $\begin{array}{l}\text { Percent canopy } \\
\text { cover }\end{array}$ & $\begin{array}{l}\text { Standard error } \\
\text { or accuracy }\end{array}$ & Source ${ }^{\mathrm{y}}$ \\
\hline \multirow[t]{3}{*}{ Photograph interpretation } & Photographic prints & 1984 & $24 \%$ & & A \\
\hline & Emerge $2 \mathrm{ft}(60 \mathrm{~cm})$ (digital) & 1999 & $25.7 \%$ & SE: $2.5 \%$ & $\mathrm{~F}$ \\
\hline & NYS Orthos $1 \mathrm{ft}(30 \mathrm{~cm})$ (digital) & 2003 & $24.7 \%$ & SE: $2.5 \%$ & $\mathrm{~F}$ \\
\hline Supervised classification & Emerge $2 \mathrm{ft}(60 \mathrm{~cm})$ & 1999 & $26.6 \%$ & Acc: $82 \%$ & $\mathrm{D}$ \\
\hline Subpixel-Cubist (specific) & Landsat $30 \mathrm{~m}$ & ca. 2001 & $26.6 \%$ & MAE: $11.7 \%$ & $\mathrm{~F}$ \\
\hline NLCD subpixel (regional) & Landsat $30 \mathrm{~m}$ & ca. 2001 & $12.7 \%$ & & $\mathrm{E}$ \\
\hline USFS Forest Density & AVHRR $1.1 \mathrm{~km}$ & 1991 & $21.6 \%$ & & B \\
\hline USFS RPA (water removed) & AVHRR $1.1 \mathrm{~km}$ & 1991 & $23.0 \%$ & & $\mathrm{C}$ \\
\hline \multirow[t]{3}{*}{ UFORE ground sample } & & 1999 & $24.4 \%$ & SE: $1.97 \%$ & $\mathrm{~F}$ \\
\hline & & 2001 & $23.1 \%$ & SE: $1.82 \%$ & $\mathrm{~F}$ \\
\hline & & 2004 & $21.4 \%$ & SE: $1.79 \%$ & $\mathrm{~F}$ \\
\hline
\end{tabular}

${ }^{\mathrm{z}}$ Results in shaded rows were generated using digital classification techniques.

${ }^{y} \mathrm{~A}=$ Rowntree (1984); B = Zhu (1994); C = Dwyer et al. (2000); D = Myeong et al. (2001); E = USGS National Land Cover Database (2001); Homer et al. (2007); $\mathrm{F}=$ USDA Forest Service, Northern Research Station, Syracuse, NY, unpublished data.

NLCD = National Land Cover Database; USFS RPA = U.S. Forest Service's Resources Planning Act; UFORE = Urban Forest Effects; AVHRR = Advanced Very-High Resolution Radiometer; MAE $=$ mean absolute error; $\mathrm{SE}=$ standard error

used as the basis for change analyses (Walton 2008); specific local analyses can produce more acceptable results. Comparison of the imagery-based estimates with field-based estimates shows good agreement. The three ground-sampled estimates do not indicate a definitive change in the urban forest canopy cover between 1999 and 2004. However, because tree cover is estimated to the nearest $5 \%$ on each plot, detection of canopy change from ground-based methods should focus on changes at the individual tree level (which trees are declining or growing), because individual tree field measures are more precise.

Accurate analysis of cover change through time is relatively difficult depending on the scale of change detection. To detect changes in overall tree cover using digital image processing, the actual change in cover through time must be greater than the uncertainty of the overall cover estimates to reasonably state that change has actually occurred. Thus, increased classification accuracy will allow for detection of smaller changes in overall canopy cover.

Mapping actual changes in canopy cover offer additional challenges. At the individual pixel level (mapping unit), uncertainty of the estimate increases relative to the uncertainty for the overall tree cover estimate. With relatively high uncertainty at the pixel level for both the base year and future year of the change analysis, mapping actual changes in canopy location is difficult. Maps of changes in tree canopy cover should include estimates of probability of change (such as in Morisette et al. 1999) to help determine the certainty of specific canopy cover change across a landscape. Methods to improve the accuracy of tree canopy cover maps (e.g., using LIDAR data to differentiate between trees and grass) could help improve the ability to detect changes in tree canopy locations.

To help determine changes in canopy cover, digital photograph interpretation can also be used. By sampling urban areas using photograph interpretation, specific locations can be followed through time using random sampling to statistically estimate changes and probability of changes in cover types for various land uses. The advantage of estimating change with photograph interpretation is that it is relatively inexpensive and accurate but lacks the capability to map specific location changes in canopy cover. Rather, canopy changes are estimated for geographic areas or land use classes.

\section{CONCLUSION}

Urban tree canopy cover analyses provide useful data on the extent and distribution of the urban forest resource as well as for estimating various ecosystem services. The use of airborne or satellite imagery to assess urban forest canopy cover can yield reliable and repeatable results if the limitations and accuracy of the imagery and classification processes are understood. Highresolution imagery, photograph interpretation, and ground-based cover analyses can produce reasonable estimates of tree canopy at the citywide scale. Medium-resolution satellite imagery is useful for city to regional analyses and can provide accurate urban forest cover and distribution information when analyzed using subpixel techniques derived from local urban training data. In mapping or determining overall canopy cover change between two digital cover classifications, it is important to understand the accuracy of the cover data and maps so that actual changes in canopy cover can be quantified.

Acknowledgments. Funding for this project was provided, in part, by the USDA Forest Service's RPA Assessment Staff and State and Private Forestry's Urban and Community Forestry Program. The use of trade, firm, or corporation names in this article is for the information and convenience of the reader. Such use does not constitute an official endorsement or approval by the U.S. Department of Agriculture Forest Service of any product or service to the exclusion of others that may be suitable.

\section{LITERATURE CITED}

American Forests. 2007. Urban Ecosystem Analysis. www.americanforests.org/resources/urbanforests/analysis.php (accessed 12/20/07).

Campbell, J.B. 2007. Introduction to Remote Sensing. 4th Ed. The Guilford Press, New York, NY. 626 pp.

Dwyer, J.F., E.G. McPherson, H.W. Schroeder, and R.A. Rowntree. 1992. Assessing the benefits and costs of the urban forest. Journal of Arboriculture 18:227-234.

Dwyer, J.F., D.J. Nowak, M.H. Noble, and S.M. Sisinni. 2000. Connecting People with Ecosystems in the 21st Century: An Assessment 
of Our Nation's Urban Forests. Gen. Tech. Rep. PNW-GTR-490. U.S. Department of Agriculture, Forest Service, Pacific Northwest Research Station, Portland, OR. 483 pp. http://treesearch.fs.fed.us/ pubs/12517 (accessed 1/3/08).

Galvin, M., J.M. Grove, and J. O’Neil-Dunne. 2007. Urban tree canopy assessment and goal setting: Case studies from four cities on the eastern coast USA. Presented to the Joint ISA-IUFRO Urban Forestry Research Group Session at the 83rd Annual International Society of Arboriculture Conference, Honolulu, Hawaii, July 30, 2007.

Homer, C., J. Dewitz, J. Fry, M. Coan, N. Hossain, C. Larson, N. Herold, A. McKerrow, J.N. VanDriel, and J. Wickham. 2007. Completion of the 2001 National Land Cover Database for the Coterminous United States. Photogrammetric Engineering and Remote Sensing 73:337-341. www.mrlc.gov/pdfs/April_07_highlight.pdf (accessed 1/3/08).

Huang, C., L. Yang, B. Wylie, and C. Homer. 2001. A strategy for estimating tree canopy density using Landsat 7 ETM+ and highresolution images over large areas. In: Third International Conference on Geospatial Information in Agriculture and Forestry, Denver, CO. http://landcover.usgs.gov/pdf/canopy_density.pdf (accessed 1/3/08).

Irani, F.M., and M.F. Galvin. 2002. Strategic Urban Forests Assessment. Maryland Department of Natural Resources, Baltimore, MD.

Iverson, L.R., and E.A. Cook. 2000. Urban forest cover of the Chicago region and its relation to household density and income. Urban Ecosystems 4:105-124.

Morisette, J.T., S. Khorram, and T. Mace. 1999. Land-cover change detection enhanced with generalized linear models. International Journal of Remote Sensing 20:2703-2721.

Myeong, S., P.F. Hopkins, and D.J. Nowak. 2001. Urban cover mapping using digital, high-spatial resolution aerial imagery. Urban Ecosystems 5:243-256.

Nowak, D.J. 1994. Understanding the structure of urban forests. Journal of Forestry 92:42-46.

Nowak, D.J., D.E. Crane, J.C. Stevens, and R.E. Hoehn. 2005. The Urban Forest Effects (UFORE) Model: Field Data Collection Manual, V1b. USDA Forest Service, Northeastern Research Station, Syracuse, NY. www.fs.fed.us/ne/syracuse/Tools/downloads/ UFORE_Manual.pdf (accessed 12/20/07).

Nowak, D.J., and J.F. Dwyer. 2007. Understanding the benefits and costs of urban forest ecosystems, pp. 25-46. In: Kuser, J. (Ed.). Urban and Community Forestry in the Northeast. Springer Science and Business Media, New York, NY.

Nowak, D.J., R.A. Rowntree, E.G. McPherson, S.M. Sisinni, E.R. Kerkmann, and J.C. Stevens. 1996. Measuring and analyzing urban tree cover. Landscape and Urban Planning 36:49-57.

O'Neil-Dunne, J. 2007. Urban Tree Canopy Assessment. www.uvm. edu/ joneildu/?Page $=$ utc/utc_main.html $\& S M=u t c / s m \_u t c . h t m l$ (accessed 1/3/08)

Poracsky, J., and M. Lackner. 2004. Urban Forest Canopy Cover in Portland, Oregon, 1972-2002; Final Report. Portland State University Cartographic Center. http://web.pdx.edu/ poracskj/ Cart\%20Center/psucc200404-047.pdf (accessed 1/3/08).

Rowntree, R.A. 1984. Forest canopy cover and land use in four eastern United States cities. Urban Ecology 8:55-67.

Small, C. 2001. Estimation of urban vegetation abundance by spectral mixture analysis. International Journal of Remote Sensing 22: $1305-1334$.

Small, C., and J.W.T. Lu. 2006. Estimation and vicarious validation of urban vegetation abundance by spectral mixture analysis. Remote Sensing of Environment 100:441-456.

Walker, J.S., and J.M. Briggs. 2007. An object-oriented approach to urban forest mapping in Phoenix. Photogrammetric Engineering and Remote Sensing 73:577-583.

Walton, J.T. 2008. Difficulties with estimating city-wide urban forest cover change from national, remotely-sensed tree canopy maps. Urban Ecosystems 11:81-90.
Wang, S. 1988. An analysis of urban tree communities using Landsat thematic mapper data. Landscape and Urban Planning 15:11-22.

Zhang, Y. 2001. Texture-integrated classification of urban treed areas in high-resolution color-infrared imagery. Photogrammetric Engineering and Remote Sensing 67:1359-1365.

Zhou, W., and A. Troy. 2008. An object-oriented approach for analysing and characterizing urban landscape at the parcel level. International Journal of Remote Sensing 29:3119-3135.

Zhu, Z. 1994. Forest Density Mapping in the Lower 48 States: A Regression Procedure. Research Paper SO-280. U.S. Department of Agriculture, Forest Service, Southern Research Station, New Orleans, LA. 11 pp. www.srs.fs.usda.gov/pubs/rp/rp_so280.pdf (accessed 1/3/ 08).

Zipperer, W.C., S.M. Sisinni, R.V. Pouyat, and T.W. Foresman. 1997. Urban tree cover: An ecological perspective. Urban Ecosystems 1: 229-246.

Jeffrey T. Walton (corresponding author)

Paul Smith's College

Routes 86 \& 30

P.O. Box 265

Paul Smiths, NY 12970-0265, U.S.

jwalton@paulsmiths.edu

David J. Nowak

Northern Research Station

USDA Forest Service

SUNY-ESF

5 Moon Library

1 Forestry Drive

Syracuse, NY 13210, U.S.

dnowak@fs.fed.us

Eric J. Greenfield

Northern Research Station

USDA Forest Service

SUNY-ESF

5 Moon Library

1 Forestry Drive

Syracuse, NY 13210, U.S.

Résumé. Avec la disponibilité de plusieurs ressources d'imagerie et de diverses techniques de classification digitale, l'évaluation du couvert de la forêt urbaine est facilement disponible pour la plupart des gestionnaires en foresterie urbaine. La compréhension de la capacité et des limites des divers types d'imagerie et de méthodes de classification est essentielle pour interpréter les valeur de couvert végétal. Une revue de plusieurs techniques de détection utilisées pour évaluer le couvert forestier urbain est présentée. Une étude de cas comparant les pourcentages de couvert avec la ville de Syracuse dans l'état de New York présente l'interprétation des multiples valeurs développées à partir de différentes méthodes. La plupart des méthodes produisent des résultats relativement similaires, mais l'estimé basé sur la banque de données nationales du couvert végétal est plus faible.

Zusammenfassung. Mit der Verfügbarkeit vieler Quellen zur Bildaufnahme und digitaler Klassifizierungstechniken ist die Untersuchung von Stadtwäldern und ihrer Kronenbedeckung für viele Forstleute einfach zugänglich geworden. Ein Verständnis für die Möglichkeiten und Einschränkungen verschiedener Methoden der Bildaufnahme und digitaler Klassifizierungstechniken ist allerdings erforderlich, um die erhaltenen Werte zu interpretieren. Hier wird ein Überblick über verschiedene Aufnahmetechniken zur Bewertung der Kronenbedeckung dargestellt. In einer Fallstudie zum Vergleich von Kronenbedeckungen 
in Syracuse, New York, werden die vielfältigen Werte, die sich aus der Anwendung verschiedener Methoden ergaben, interpretiert. Die meisten Methoden produzieren relativ ähnliche Ergebnisse, aber die Schätzung nach der National Land Cover-Datenbank liegen weit geringer.

Resumen. Con la disponibilidad de muchos recursos de imágenes y diferentes técnicas digitales, la evaluación de la cobertura del bosque urbano es fácilmente accesible para la mayoría de los dasónomos urbanos. El entendimiento de la capacidad y limitaciones de diferentes tipos de imágenes y métodos de clasificación es esencial para interpretar los valores de la cubierta arbórea. Se emplea una revisión de varias técnicas de sensores remotos para evaluar la cobertura del bosque urbano. Un caso de estudio comparando los porcentajes de cobertura para Syracuse, New York, U. S. interpreta los múltiples valores desarrollados usando métodos diferentes. La mayoría de los métodos producen resultados relativamente similares, pero la estimación basada en la National Land Cover Database es mucho más baja. 